that $17 \%$ of lung cancers among non-smokers are attributable to high levels of exposure to cigarette smoking during childhood and adolescence.

Given all this, not surprisingly the most recent British plea for action has come from a group of doctors. In early December the British Thoracic Society called for a united coalition of doctors to pressurise the government into introducing a model tobacco act. The new organisation would unite all those currently working on smoking and health, while the key features of the act would mirror some of the European Community directives, and also include regular tax rises, more education for the public, and more resources for smoking cessation. And the special needs of the Third World should not be forgotten, for without expert help from the West these countries are powerless to counter the epidemic that will ensue from the migration of tobacco companies there.

Such political moves are welcome, but they need reinforcing by an approach directed at individuals and in particular in health workers and politicians. The time has surely come when all those working in the NHS - and certainly all health ministers and officials - who continue to smoke should ask themselves whether they are morally justified in presenting such a dissonant message to the public. A similar personal approach should be made to members of the new cabinet, where at least two members, Mr John Major and Sir George Young, are on record as sympathising with antismoking groups.

It should also not be forgotten that, despite its brave directives, the European Community spends nearly $£ 800 \mathrm{~m}$ a year on tobacco subsidies, $£ 150 \mathrm{~m}$ of these borne by the United Kingdom. The health service needs more money and needs to make the best of its facilities. Where better to start than by following the example of other countries in tackling a largely reversible epidemic of wasteful, economically damaging disease.

Editor, $B M \mathcal{F}$

\title{
Cancer services
}

\section{Patients with cancer need compassionate care from the start of their illness}

The last weeks of the life of most patients with cancer are less harrowing now than they were $20-30$ years ago; the philosophy of the hospice movement has permeated widely throughout the NHS, influencing doctors, nurses, and other health workers. But although physical symptoms may be at their worst in the terminal stages of cancer, much of the mental distress peaks early on - as soon as the diagnosis is suspected and long before treatment is even discussed. The general practitioner's first hints as he refers the patient to hospital, the hospital doctor's evasive insistence that he can't say what's wrong until the tests are completed, the family's uncertainty about whether or not to acknowledge the fears at the back of everyone's mind: all these conspire to make the patient feel isolated, abandoned, and often frankly terrified. At this stage, too, patients may begin to ask philosophical questions such as "Why me?" or "What did I do to deserve this?" and to reexamine, perhaps for the first time for many years, their beliefs about religion and life after death.

\section{Lack of advice and support}

Studies of patients with cancer and of their relatives after the patient's death continue to bear witness to the lack of advice and support when the disease is first recognised. These issues were discussed recently at an informal workshop of doctors, health workers, and patients. The meeting was given accounts of some pioneering cancer support services within the NHS that are financed in part by voluntary funding and was told of plans for fund raising for further examples.

What does a cancer support service provide? Firstly, and most importantly, it creates a working atmosphere in which patients and their families can feel confident that when they ask questions and express their fears and doubts they will not be fobbed off: time will be found and someone will answer the questions or find the answers if they don't know them.

A typical service will be a building or some rooms on the site of a hospital that will provide day care facilities for patients. In addition to conventional physical therapies it will also have arrangements for emotional support and counselling by a combination of volunteers and health professionals. It will have a telephone information services for patients and their relatives backed up by written materials and videos. Several of the pioneer services have also offered patients a range of alternative and complementary therapies, ranging from nutritional advice to pain relief by acupuncture and therapeutic massage. Clearly there is a demand from patients for this sort of provision - and hard line sceptics who condemn all such therapies as unproved should note, firstly, that some clinical trials have shown (for example) that acupuncture is an effective antiemetic and that a wide range of complementary treatments are available to patients attending the cancer rehabilitation unit at the Royal Marsden Hospital. Times have changed, and medical attitudes need to change with them.

We live, indeed, in an era of consumer rights, and the basic care that all patients with cancer may reasonably expect is now becoming agreed. Technical competence in diagnosis and management is necessary but not itself enough. Clinicians should now recognise that the moment a patient is suspected of having cancer emotional support needs to be provided. Clinicians who do not feel competent to give that support (or haven't the time or the inclination) should recognise that they have an obligation to delegate the task to some other health professional who has been suitably trained and who sees the task as a priority. If there is a cancer support services on site the patient may be referred there.

\section{Role of cancer adviser}

Wherever the information and emotional support are provided, they should be given to the patient and his or her "significant other"-spouse, relative, companion, or whatever. In particular, information and discussion of treatment options should take place simultaneously with the patient and the "other"-for the practical reason that they are both told the same and to avoid any suspicion that facts are being withheld from the patient.

What does a cancer adviser or counsellor do apart from 
explaining what is going on in terms of diagnosis and treatment? He or she assesses the patient and the "other," attempting to identify their physical and psychological needs; when possible the adviser tries to help them solve their problems and to facilitate personal growth, which means steering and encouraging the couple to acknowledge what is happening to them and to come to terms with it. The adviser should be able to refer patients for specialist care when necessary (psychiatric treatment for depression, for example). But the adviser is also the patient's advocate and can help him or her to have the courage to ask the clinician for a review of treatment options and possible outcomes - and perhaps decide to call an end to active treatment.

Provision of cancer care services will be expensive, even if paid for in part by local fund raising and charitable sources. I hope that the big cancer relief charities will put some of their knowledge - and their money - into the movement supporting the growth of these services. If such units are to be successful, however, they will need to be seen and to function as part of the mainstream NHS care of patients with cancer. That will require national guidelines on structure, staffing, and financing as well as on the work that the units do. It will require that the treatments and interventions offered to patients are validated and provided by trained staff. Most important, it will require that the treatment, advice, and support given to patients are monitored and assessed. When treatment is in any way controversial rigorous medical audit is the key to convincing the doubters.

TONY SMITH

Associate editor, $B M \mathcal{F}$
Each month, in a postbag of some 270 letters and 400 papers, the $B M F$ receives at least one article that provides food for thoughts of an uncomfortable kind. Written by a patient or a relative of a patient, these letters and personal papers have a common thread: how a particular medical problem was mishandled by the profession. The nub of the complaint is usually less about the failure to make the right diagnosis or to prevent avoidable complications than about a perceived failure of the doctors concerned to communicate adequately and show that they cared.

Not surprisingly, these articles tend to relate to sticky clinical problems: the patient with persistent symptoms but in the early stages of disease with repeatedly negative test results, for example. One woman with advanced neurological disease sent a letter last month expressing her "distress and isolation... and the painful, humiliating experience" of having her early neurological symptoms and signs dismissed (as psychogenic).Chronic incurable disease is another problem that seems to trigger letters expressing anger and disillusionment about doctors' interest tailing off once the disease is diagnosed. In a recent personal view a neurologist spoke of incurable disease as "an area between rehabilitation and terminal care which places the highest demands on doctors' skills." He went on to state that "students must not be biased against palliative treatment such as physiotherapy, occupational therapy, counselling, and supportive psychotherapy."

\section{Teaching communication}

In its recommendations on basic medical education the General Medical Council states that medical students should be taught to "communicate clearly, sensitively, and effectively with patients and their relatives and with fellow professionals." How individual medical schools choose to do this is up to them, but over the past few years formal teaching of communication skills has assumed increasing importance in the undergraduate curriculum. Some approaches are particularly imaginative; Guy's Hospital employs actors to play the part of patients and their relatives in a week long advanced communication course. Students are recorded on videotape as they take histories, counsel patients, break bad news, and so on, and the video is then used in group discussions. Teaching along similar lines is also part of general practitioners' vocational training.

Outside the teaching circuits awareness that patients are consumers to whom the health service should be more responsive has spawned much political rhetoric and numerous reports. ${ }^{34}$ Equally numerous papers have been published on what patients want from their doctors, especially about the style and length of the general practitioner's consultation. ${ }^{56}$

But brave new communication initiatives and paper stockpiles of theoretical knowledge on how to increase patient satisfaction are hard to translate into the realities of patient care. This is especially so of care in hospital, where enthusiasm for improving communication skills and responding to patient preference seems muted. In a paper delivered at an Office of Health Economics symposium two years ago Professor Sir David Weatherall spoke of the problems posed by the rapid turnover of patients in hospitals in which the corporate spirit was dwindling. He cited a study showing that $30-50 \%$ of inpatients experienced a loss of personal identity and suffered as a result of poor communication. ${ }^{7}$ How much worse might a similar assessment be now? And is the standard of pastoral care appreciably better in general practice? Anecdotal reports suggest that the new general practice contract has left doctors with less time than ever to communicate with their patients.

\section{Patients' vulnerability}

Irrespective of the problems that now face the NHS and those who work in it, however, there can be little justification for cavalier treatment of patients or their relatives. ${ }^{8}$ Even the briefest spell on the other side of the desk or in a hospital bed gives blinding insight into patients' vulnerability and of their need to be listened to, treated with respect, and given full, unhurried, jargon free explanations. ${ }^{910}$ Simple gestures of kindness and encouragement go a long way - as does the occasional admission of fallibility. One of the more poignant personal views we published concluded as follows. "I am disappointed that the consultant did not write back as he promised. He never discussed what went wrong with my mother either. I suppose that he was afraid of litigation. But if he had admitted his mistake we would feel less bitter about the whole agonising episode. I still feel let down. I wish he'd said sorry."11 